\title{
Analysis of Traumatic brain injury related to Kite flying festival: An institutional study
}

\author{
Manish Jaiswal, Somil Jaiswal, Bal Krishna Ojha, Sunil Kumar \\ Singh, Anil Chandra, Chhitij Srivastava \\ Department of Neurosurgery, King George's Medical University, Lucknow, U.P., INDIA
}

\begin{abstract}
Introduction: Makar Sankranti or Uttarayan is the kite flying festival in India. The festival marks the end of winter and the beginning of summer as the sun moves to the Tropic of Cancer bringing with it longer and warmer days. But it turns into a difficult day for those who are hospitalised after suffering from kite flying related injuries. Aims \& Objectives: The objective of this cross sectional study was to review the demographics, causes injury, severity, treatment and outcome of traumatic brain injuries in victims of this kite flying festival who were admitted in department of Neurosurgery on the occasion this year in January. Patients \& Methods: A total of 46 traumatic brain injured patients was admitted under Neurosurgery Services that day, out of which 18 cases were related to kite flying related injury. Data of these 18 patients were analysed and outcome were measured at discharge. Result: kite flying festival related neurotrauma increase $39 \%$ more emergency admission burden as compared to routine days in neuro-emergency ward. Most common cause of head injury among them was fall from roof. Majority of them had mild head injury. Associated injuries to other part of body were present in $46 \%$ patients. Conclusion: Children were most affected due to unsupervised kite flying on roof and road side catching of kites. Depressed fracture was commonest type of traumatic brain injury. Strict attention to safety measures and parental supervision while flying kites can avoid many preventable injuries to life.
\end{abstract}

Key words: kite flying injury; traumatic brain injury; festival related trauma 


\section{Introduction}

Any festival having some kind of sport or game on the occasion has certain injuries unique to it, even a seemingly harmless and docile sport like flying a kite. Injuries of kite flying activity are commonly sustained by kite-flyers, kite-runners, riders of two wheelers and pedestrians [1,2,3]. The distribution of Kite related injuries varies over different locations and regions and is influenced by the local cultures and traditions, like there is an epidemic of kite related injuries during the festival of Makar Sankranti in the states of Gujrat, Rajasthan, Uttar Pradesh and other part of north India in January or the Basant festival in Peshawar, Pakistan [4,5]. While a few articles do speak about the spectrum of kite related injuries $[6,7,8]$, exclusive literature focusing on traumatic brain injuries related to the kite flying festival is seldom found.

\section{Patients \& Methods}

It was a hospital based observational cross sectional study of all cases of traumatic brain injury victims admitted in neurosurgery emergency on the day of kite flying festival (Makar Sankranti). A total of 46 traumatic brain injured patients was admitted under Neurosurgery Services that day, out of which 18 cases were related to kite flying related injuries. Data of these 18 patients were analyzed for demographic details regarding age and sex of the patients, time since the injury to hospital admission, cause of head injury, severity of traumatic brain injury based on the Glasgow Coma Score, findings on CT scan of the brain, treatment provided and outcome based on the Glasgow Outcome score. Outcome was measured at discharge.

\section{Results}

There were 18 (39\%) patients who were admitted for traumatic brain injuries related to kite flying festival on that day along with other 28 head injury patient admission unrelated to this kite flying accident. Out of 18 patients, there were 17 males (94.5\%) and 1 female (5.5\%). There were patients of all age groups. Most affected age group was 5-15 years. The age distribution of patients is shown in (figure 1). Mean age of patients was 11 years (range 5-38 yrs).

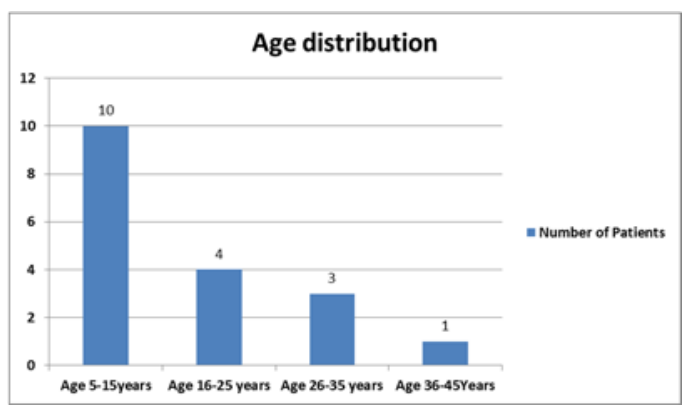

Figure 1 - Age distribution of kite flying festival related traumatic brain injury patients

Fall from roof was the commonest cause of injury in 12 patients (67\%), followed by a fall on ground and collision with motor vehicles during running on road for catching kites in 4 patients (22\%). Two patients (11\%) sustained an injury due to fall from the tree during kite removal from tree (Figure 2). 


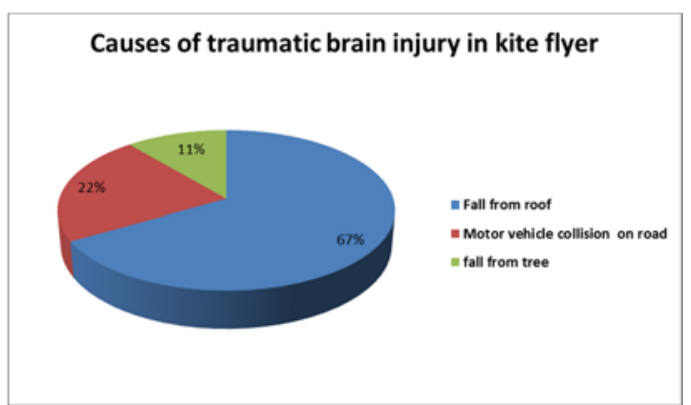

Figure 2 - Causes of traumatic brain injury in kite flying related accident

$13(72.22 \%)$ had mild head injuries, 4 patients $(22.22 \%)$ had moderate head injuries and 1 patient (5.5\%) had severe head injuries (Figure 3). CT scan was normal in 7 patients (38.8\%). There were depressed skull fractures in 5 patients $(27.7 \%)$, extradural hematoma in 2 patients $(11.11 \%)$, intracranial hematomas in 3 patients $(16.6 \%)$ and diffuse cerebral edema in 1 patient $(5.5 \%)$.

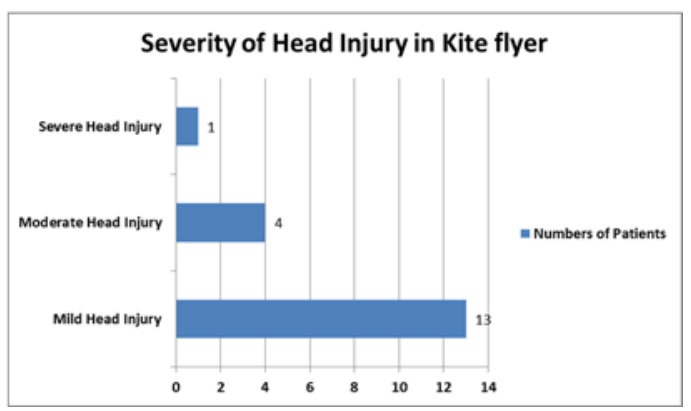

Figure 3 - Head injury severity in kite flying related trauma

Eight patients (44.4\%) had associated injuries to other parts of the body. 3 patients had spinal injuries, 2 had rib fractures, 2 patients had facial injuries and 1 had abdominal visceral injury.
Eight patients (44.4\%) underwent surgery, which included elevation of depressed fracture, debridement and suturing of large scalp laceration in 4 , spinal fixation in 2 patients, craniotomy and evacuation of extradural haematoma in 1 patient \& decompressive craniectomy in 1 patient. All associated injuries were treated nonoperatively.

Mean hospital stay was 9 days (range 3 38 days). The outcome was assessed at the time of discharge. At the time of discharge 14 patients $(77.7 \%)$ had a good recovery, 2 patients (11.1\%) had moderate disability, 1 patient $(5.5 \%)$ had severe disability and one patient died. During the hospital course, one 6 years old child with compound depressed fracture died of meningitis.

\section{Discussion}

Most of the injuries sustained during kiteflying, reported in literatures were due to falls, cuts, head injuries or fractures $[3,4,9]$. People were also injured while on streets, riding on motor bikes, children catching wandering cut off kites on the roads [10]. Teenagers sustained most injuries due to falls related to kite-flying activities [11]. In traffic accidents the major consequences were fractures and wounds. Head injury was the major consequence of falls. Kite flying might look like blossom floating in the wind, but it is one of the dangerous sports in the world. Every year this gruesome game has left hundreds of people with sustained injuries and disabilities and many others dead in India $[4,5,7,9]$. Among all age groups this is a popular sport in children and young and thus more injuries are observed in younger age groups $[12,13]$. In this study a decrease was observed in the 
number of injuries with increase in age. Prevention of childhood injuries is of great importance to both individuals and society, but unfortunately, has largely been either excluded from attention or treated in an inappropriate manner.

Nadir Mehmood et al. in their study mentioned falls and head injuries while flying kites to be the most important cause of morbidities [14]. Falls while flying kites are a leading cause of the global burden of injury to children resulting in more than 37,000 deaths annually for those aged 15 years $[1,3,14]$.

Therefore proper preventive measures, increasing awareness about the possible effects of such a sport and offering social counselling to the families can help to reduce the incidence of injuries in our population. For obtaining this objective, the need is to increase the awareness of the parents and society and to reduce the incidence of such injury; this study is a small part of that investigation.

\section{Conclusions}

Children were most affected due to unsupervised kite flying on roof and road side catching of kites. Depressed fracture was commonest type of traumatic brain injury. Strict attention to safety measures and parental supervision while flying kites can avoid many preventable injuries to life. A preventive program, legislations and educational reinforcement should be promoted to decrease the number of kiteflying-related traumatic brain injury.

\section{Correspondence}

Dr. Manish Jaiswal

Assistant professor,

Department of Neurosurgery.

King George's Medical University
Chowk, Lucknow, U.P., INDIA-226003

Email:manishmlnmc@gmail.com

Mobile No. 8933816028

\section{References}

1. Charles M. Court-Brown, Alexander M. Wood, Stuart Aitken. The epidemiology of acute sports-related fractures in adults. Injury, Int. J. Care Injured (2008) 39, 1365-1372.

2. Chaudhari N. Adolescent Injuries. Indian Pediatr1990; 27:1261-1267

3. Coggan C, Patterson P, Brewin M, Hooper R, Robinson E. Evaluation of Waitakere Community Injury Prevention Project. Inj Prev 2000;6:130-4.

4. Colver A, Hutchinson P, Judson E. Promoting children's home safety. BMJ 1982;285:1177-80.

5. Court-Brown CM, Caesar B. Epidemiology of adult fractures: a review. Injury 2006; 37: 691-7.

6. Guyer B, Gallacher SS, Chang B, Azzara CV, Cupples LA, Colton T. Prevention of childhood injuries: evaluation of the statewide childhood injury prevention program (SCIPP). Am J Public Health 1989;79:1521-7.

7. Haddon W, Baker SP. injury control. In Clark DW, MacMohanB, eds.Preventive Medicine. 2 no edn, Boston, Little Brown \&Company, 1978; 172.

8. Kimati VP. Childhood accidents in Dar-e-Salaam. Trop. Geogr. Med. 1971, 29: 91-95.

9. Neto JBR, Ferreira GC, Filho ALS, Fontes MOBQ, Bomfim F, Abrantes WL. Kiting injuries: report of two cases and discussion. J Trauma Injury Infection Crit Care 2000;48(2):310.

10. Paul CL, Sanson-Fisher RW, Redman S, Carter S. Preventing accidental injury to young children in the home using volunteers. Health Promot Int 1994;9:241-9. 11. Sitaraman S, Sharma S, Saxena S, Sogani KC. Accidents in infancy and childhood. Indian Peditr. 1985, 22:815-818.

12. Tendon J.N., Karla, A., Karla, K., Sahu, S.C., Nigam, C.B. and Qureshi, G.U., 1993. Profiles of accidents in Children. Indian Pediatrics 30: 765-769.

13. Vineis P, Ronco G, Ciccone G, Gogliani F. Home injuries in children: a population-based intervention trial. Epidemiology 1994; 5:349 -51.

14. Mehmood N, Khwaja ZH, Ramazan S, Quddus A. Kite-flying associated injuries in Rawalpindi. Ann Pak Inst Med Sci 2010;6:116-9 